\title{
The Role of Media in Supporting Communication in Cultural Institutions. Case Study: Communicating Media Art MICHELA NEGRINI, UNIVERSITTY OF LUGANO
}

\begin{abstract}
Please note: In this research, the term 'media' references the tools used to store and deliver information and to communicate, including by sharing and discussing information and referring to activities that integrate technology. It also applies to the tools, materials and techniques used by an artist to produce a work. On the contrary, the term does not imply 'mass media' such as TV, newspapers, etc...
\end{abstract}

Since the 1960s media has entered the "world" of art and the "space" of museums and galleries, questioning every fundamental assumption in museum practice. Focusing on communication, this investigation explores the role media and technology play in contemporary art museums, influencing the public's practice and consume.

The central questions being:

- how media are engaged in supporting communication in cultural institutions?

- how media and technologies influence access, contact and enjoyment of a work of art?

While museums become a media laboratory, experimenting technology and its different uses, media acquire a strategic role for communication in cultural heritage, including social media, and more generally Web 2.0.; web sites, indeed, are becoming web applications and web visitors are becoming users and forming communities. As the field of research is variable and unstable, this work aims to develop a communication strategy for contemporary art, focusing on the case study of communicating Media art. The goal is to create a virtual space, a bridge between time, space and geography, a venue in which Media art projects find a place and where everyone is invited to join in and participate, spreading and accessing Media art around the world. This web site warrant a community spirit of activity and engagement, fostering art projects, videos, interviews, photographs, etc... Impact studies will support the strategy result.

An interdisciplinary approach - including ethnographical as well as historical, archival and literature research -allows this work, which is carried on research, conversations with curators, museum directors, artists, new media professionals and experts, observing the contradiction between new media culture and museum culture and the participation of museums to the new media fray. An anthropological approach compliments the research, through participatory observation in museums, galleries and site-specific events.

\section{KEYWORDS}

Media art, cultural heritage, media communication, social media, web 2.0 


\section{INTRODUCTION}

In contemporary art, the generic term Media art is used to describe specific types of works created from the 1960s which to a significant extent are related to or created within a technological medium. In reference to disciplines such as video, electronic and Internet art, and to works related to telecommunications and mass media, Media art poses unique challenges to museums in terms of presentation and communication. Since the 1960s media has entered the "world" of art and the "space" of museums and galleries transforming the traditional perception of artistic practices and the space it occupies. Installations, performances and videos oppose sculptures and paintings. Moving images oppose static image. Live (performances) to still (images).

The nature of Media art and the space it occupies is distinct from traditional art objects and from the early 70s Media art has posed museums and cultural institutions with difficult problems. Media art indeed questions every fundamental assumption: the role of spectators as well as the role of museums in exhibiting and communicating; the nature of a Media artwork, its preservation and presentation. In fact, whereas traditional art objects are usually static and inactive, Media art works are generally time-based and interactive. Furthermore, the technological equipment and software used for Media art projects age at extreme speed. All these things museums are based and structured upon are now thrown open to question, a crucial aspect of which is the role of the museum in communication. However, whereas current research on contemporary art has an emphasis on the way works of art are created, artistic intent and the strategies to document artistic processes, communication of Media art works - if compared to the so-called traditional forms of art - has not been extensively explored yet. At present time communicating Media art has become very complex. Museums have become media laboratories, experimenting with technology and exploring its different uses.

The role media plays for a strategic communication in cultural heritage, including social media, and more generally Web 2.0, has grown rapidly. Websites are becoming web applications and web visitors are becoming users and forming communities. Presently, producing cultural experiences could be accomplished by performing an act of co-creation between organisation and participating audiences, and not only between artist and public. Furthermore, the use of media must address the specifics of venue and audience to serve museum needs. They must be designed to support conceptual and aesthetic standards, and must work all the time, forcing on the producer a keen awareness of the audience and making the professional questions the relationship between audience and artefact, between museum and the outside world.

Indeed, museums, galleries or art spaces in general need to communicate within a customized social networking framework. In fact, viewers no longer watch art works, but watch databases instead. Browsing online, the visitors search one list after another, allowing themselves to be led by an endless database. This tendency may appear as the cultural constant of the early 21 st century. Since 2005 , the explosion of video content on the web has set free a new media universe, made possible by a number of free web platforms and software tools that enable people to share their media and access media produced by others, moving from media to social media. 
Focusing on communication, this investigation explores the role media and technology play in contemporary art museums, influencing the public practice and consume. The central questions are:

- how media are engaged in supporting communication in cultural institutions?

- how media and technologies influence access, contact and enjoyment of a work of art?

This work observes the contradiction between new media culture and museum culture and the participation of museums to the new media fray.

As the field of research is variable and unstable, focusing in particular on Media art, this work moves towards the development of a communication strategy for contemporary art. The aim is to create a virtual space, a bridge between time, space and geography, a venue in which Media art projects find place and where everyone is invited to participate, spreading and accessing Media art around the world.

\section{DEFINITION OF MEDIA ART}

While there is no specific and single definition of Media art, there are some common and peculiar characteristics such as intangibility, 'liveness', fluidity, variability, connectivity, interactivity, and 'eventness'. Media art is a generic term in contemporary art, and this term is mainly used to describe specific types of artworks created from the 1960 s until the present. The term itself has become widely used since the 1990s.

At present Media art embraces many other distinct forms under the category of New Media art, such as Net art, Virtual Reality, Robotic and Agents, Artificial life forms, and Digital art. Moreover, the term 'plurimedia' has been introduced to describe the use of more than one medium in the same art work, as a crossover and combination of media (see also: Greene, 2004., Levinson, 1997., Moser, 1996., and Weibel, 2001).

These sub-categories involve the use of Internet, browser-based art, hypertext, real-time performances that synthesize voice, sounds and data; interactive synthetic world and environment that require the use of head-mounted display or glove-input devices worn by the user/spectator; software robots and computer virus art; the use of genetic engineering to make art; arts that use digital means (King, 2002).

Indeed, Media art and technological development grow on parallel tracks influencing one another but causing a very quick obsolescence of Media art projects. Since the 1960s media has entered the world of art and museums and galleries space and since the 1970s, Media art has become a category in itself, with a growing number of artists experimenting with technological means. In less than a decade artistic practices marked significant changes, particularly in the field of Media art. As artists began to question and explore the notion of space and physicality, the very idea of medium underwent a crisis.

Media art has rapidly transformed the traditional perception of artistic practices and the space they occupy, raising the conceptual approach to viewer participation and social space. A time-based media work is best understood in its installed/displayed state as a dynamic system. This system transforms the media into video and sound and makes it accessible and enjoyable to viewers. A peculiarity of Media art is the context of a precise environment. Such works are meant to be experienced, perceived and consumed by the public in specific spaces 
as part of a dynamic system. Bodily and emotional sensations aroused by media have a long history: magic spectacles have taken place since the 17th century. Lanterna Magical, Phantasmagorias were meant to merge the spectator in a fantastic spectacle and performance of illusion, not to mention Plato's Cave allegory, where the same idea and concept were already taking place. The synaesthetic experience in that case implied the available technologies and environment, a mix of images, lights and sounds. From then, to the recent past, Media art indeed has become a mainstream art form representing some of the most important, exciting and emblematic artistic creations of our time (and space).

Conservators today are interested in the relationships of the Media work's components, their eventual decaying and obsolescence. Many studies are focused on the representation of Media art in museums' environment.

What this work aims to investigate is the possibility of creating a virtual place where these works are gathered, information is given, and images, interviews, discussions are hosted. A place where professionals can discuss about Media art and where people interested in this field can access for information and conversation.

Displaying the present in fact is not a wrong mission and has no longer to be considered, in Foucaultian heritage, asylum, hospital, and prison (Foucault, 1980). In this new era of visual culture, the opposition between exhibition environments, the physicality of objects and their modes of interaction, the identity of a gallery, its traditional space of aesthetic contemplation, and the newer interaction and experience given by virtual environment is providing newer areas of analysis.

Consequently, this virtual place aim is to raise awareness and communicate Media art, allowing people who are already familiar with the subject to find more organized material and reaching people who are not yet accustomed by Media art, but share potential interest. Based on a user-centred design, this website applies AWARE (Analysis of Web Application Requirements), a goal-oriented engineering method for defining and analyzing requirements for web applications, and IDM (Interactive Dialogue Mode), a design model tailored for multichannel applications (Paolini, et al., 2006). AWARE is a goal-based approach and presents the following essential features. It offers simple primitives enabling to document and specify goal-oriented hypermedia requirements and it provides a set of conceptual tools useful for describing and reasoning with website requirements. It identifies stakeholders and their goals as the core of requirements analysis. It also provides requirements taxonomy, used to define the so called requirement dimensions, to tie requirements to hypermedia conceptual design and help organize the design activity accordingly. Content, Structure of content, Access Paths to Content, Navigation, Presentation, User Operation, System Operation, Interaction represent the basic of dimensions proposed by AWARE. However, it can be extended accordingly to the specific design needs. IDM (Interactive Dialogue Mode) is a designed model based on dialogue primitives and presents distinctive features. It provides a few set of primitives and simple graphic notation. It is useful for brainstorming and generating ideas at early design stage. It is cost-effective and modular. 


\section{ARCHAEOLOGY OF MEDIA AND (MULTI)MEDIA ART: THE RED THREAD}

Since the beginning of the 20th century, decades before the coming of the multimedia era, the whole idea of the sensorial association and combination of sounds and visions sprang from the nascent avant-gardes. In that same period, the concept of synaesthesia softly invaded literature, painting and music and the first half of the 20th century offered the public an incredible production of works and technical machinery able to merge and swirl in a new and original way the senses of hearing and looking. 1895 represents a crucial year, when the Cinématographe, an instrument for the recording and projection of living motion invented by the Lumiérè brothers was publicly used in Paris, offering them the conventional paternity of founders of cinema. Alongside this technology of movement, the past century witnessed incredible technological evolutions (See: Crary, 1990., \& Pisters, 1998).

I will try to trace a thread to connect the archaeology of media and (multi)Media art. From the very first cinema, to TV, to monitor; from live music, to radio, to synthesized music, in about one century sound and vision are able to cross the threshold of skin (i.e. cyber surgery) and finally penetrate the human senses bringing to newer visions and different applications of the original uses of the cinematic apparatus as we typically relate to. Indeed, in the $20^{\text {th }}$ century science has felt a need for instantaneous representation. In this context Etienne-Jules Marey's chronophotography experiments have to be inscribed, whereas cinema has attempted to erase the time of representation, offering images which can be perceived as happening in real time. In reference to discipline such as video, electronic and Internet art and to works related to telecommunication and mass media, Media art poses unique challenges to museums and art spaces. Media art, today, offers images created and perceived in real time. Software and Hardware offer the tools of making 'art' to a broader range of users. In this mass production, though, a multitude of works are produced at increasing rate. Can museum practice go along with this scene? How do technologies influence access, practice and consume of a work of art? How does Media, intended both as a work of art or as a communication tool and technology, challenge the conventional object-centred approach museum, galleries and exhibition spaces in general are confronted with and introduce virtual communities and environment as field of analysis, participation and interaction? According to Kerry Brougher, Jeremy Strick, Ari Wiseman and Judith Zilczer, drawing the Media art world gives the opportunity to look at Media art in a wider perspective (Brougher et al., 2005).Since the first exhibition presented by Nam June Paik in 1963 at the Rolf Jarlings Gallery in Wuppertal, Germany, entitled 'Exposition of Music -Electronic Television', video has undergone a significant development and it is nowadays recognised as a form of expression in itself. In 1965, the introduction of portable videotape recorder and player created the potential for alternative production by placing the tools of the medium in the hands of single artists and since then, art met media. Video indeed placed itself as the opposition to the dominant institution of commercial TV, becoming the contemporary art form. During the 1960s art involved intertextual practices. Artists sought to detach themselves from dominant modes of expression, primarily in the use of the signifier and its technology, necessitating investigation into not only the medium's inherent properties but also the political structures employed in television.

Nevertheless, the phenomenology of viewing video work is influenced by the (broadcast) television experience, and artists had to be aware that the viewers were subconsciously moved by their TV-visual expectations. A conceptually provocative approach both to form and content induced engagement rather than alienation as well as seductive and manipulatory expectations in the viewing process. Early video art works 'messages' were implicit, 
sometimes metaphoric and clearly transgressed the boundaries of a formalist aesthetic so as to stand as signs of a political independence outside the confines of both orthodox modernism and institutionalised TV. The intent was not to decentralise the TV industry, but an attempt to claim an autonomous practise of the medium itself. Within a few years, increasing technologies, such as digital and electronic devices, software and hardware, accelerated sound and vision (media) art adventures in perception.

The recent past has been characterized by the advent of the so-called New Media art. 1989 marked a drastic change in culture and society and a radical evolution of electronic art. According with F. Sumitomo and Y. Shikata, five key-works could trace the major lines of such phenomenon: Time, Space, Body, Public and Generative. Parallel to them, flow technology, theory, art-works and exhibition spaces (Suminitomo \& Shikata, 2005). The analysis of such components is the key to understand the evolutions and the change of Media and New Media art. In Sumitomo and Shikata's terms, Media art's evolution is strictly linked with the technological improvements as well as society's changes that have occurred throughout the years. These continuous connections with devices, society, culture and with the past in general highlight the self-referential aspect of Media art as well as its attempts to leave the past behind. The cameraman/artist creates images through technological devices, penetrates deeply into a visual reality. This environment of "real time" visual representation offers the analogy cameraman/user: both are professionals who share the same attitude in being observers. In both cases, in fact, they do not play the role of mere spectators, but on the contrary, they intervene into their "objects". Not only the distance between perception and representation can be shortened, but also distances between technologies and the represented objects (Benjamin, 1936).

In this time of new frontiers, the last few years have witnessed in audio-visual production deep and intense modifications, offering the metaphorical image of a map of a constantly moving territory. Lines forming this map keep moving overlapping other lines in different directions. It is today an uncontrollable territory: technological changes have thrown the art world in a sort of abyss of creative possibilities. Fusions, hybridism, exchanges between video environment and interactive media. This progression of changes, fusions and contaminations reveal something about what consumers of art experience: changes in social life, and the speed of interactions and symbolic exchanges typical of nowadays. 
All this is revealed in the intense movement of contemporary art. Technological improvements and easy access to media has influenced the Media art world. Not only creating art works has changed, but distributing, archiving and communicating them too. Media art represents a new chapter in what used to be a field for few. The accessibility of new electronic and digital technologies questioned old traditions in the use of sound and images. The 20th century opened, as far as art concerns, with groups that interrogated a changing society and especially fought against the institutionalisation of art. Dadaism, Symbolism, Futurism and Surrealism in different ways and with different techniques opposed themselves to traditional forms of art and aimed to merge art together with daily life. In the same years, the principle of montage took place. At the end of that same century, we have witnessed a medium enlightening the crowds and the principle of 'mixing' replaced the montage. With the coming of digital video editing this trend became even more apparent. Regardless of the advantages, disadvantages and meaning of this new phenomenon, the development of new technologies lead to a stronger connection and manipulations in which everything is mingled together, which has inspired many artists. The audience is called to participate to this crossover of discipline and situation and today the need for mash ups becomes crucial and the future for portals seems to be aggregation.

Indeed, while the $20^{\text {th }}$ century has been characterized by the video/film, the early 21 st century set the beginning of social video. Many changes have occurred in a short period of time and when looking at the Web 2.0 concept, it appears that while in the 1990s the web was mostly a publishing medium, in a decade it has increasingly become a communication medium: communication between the users take place through a variety of forms beside e-mail: post, comments, reviews, rating, photos, video, etc... What does this trend mean for culture and in particular for contemporary art? The number of people participating in social networks, sharing media and creating content is remarkable. Social media platforms give users unlimited space for storage and numerous tools to organize, promote and broadcast their thoughts, opinions, behaviour, and Media to other users. Social media are adaptable, mobile and flexible. According to Tim O'Reilly who, in 2004 originally coined and defined the term Web 2.0, one very important feature of Web 2.0 application, in fact, is 'design for hackability and remixability' (O'Reilly, 2005, n.p.).

\section{COMMUNICATING MEDIA ART}

Since ancient time, patronage of art has been practiced by the Church, the State and private individuals. Commissioning art works has represented a strong dynamic in the relation between patron and artist, balancing patron's desires and artist's wishes, especially during the Renaissance, when the strict link between arts and importance of the patron flourished.

In this dynamic of patronage, Media art represents a change and it is unbalancing the preexisting system. The growth of Media art has been wild and uncontrolled and not taken into account by museums and gallery. On the other hand, in the late 20th century, Media art, installations, and electronic as well as digital art have entered the contemporary museum scene. However, the continued development of technologies expands the possibilities and forms of Media art to an uncontrolled extent. Traditionally, museums have had a specific role, such as collecting, preserving and presenting artworks. Media art has changed the traditional museum practice and museums that wish to follow contemporary art have to expand their mission. There are still some specific venues and patrons for Media art and installations, such as the Venice Biennale in Italy, Documenta in Kassel- Germany, PS1 in Queens- NY, just to mention some of the existing ones. However, the role of the on-line/web 
environment has grown exponentially in the past decade offering a space free of control and restrictions, where artists can work, create, experiment and communicate challenging not physical boundaries but the limits of this technological and virtual environment. In this newer context restrictions and limits are reversed and what in a museum space could have been considered a barrier, in the on-line space represent the technological ability of the artist. The medium itself sets limits, the artist's commission is the overcoming of such limits and the virtual space itself becomes a tool for creating art. Artists employ new technologies to engage with the traditions of art history, to create new forms of art, to re-interpret and re-explore old ones, and to depart into fields of activity normally beyond the artistic realm. For Media artists indeed the use of technology is a poetic instrument and represents a means of individual expressions, as canvas did for past generations of artists.

Indeed, Web 2.0 practice redefines content: cultural object, cultural production and consumption, and communication. What's the benefit of contemporary art - and in particular of Media art - in being easily available online? From the 1960s until today Media art has undergone very many different stages and today it has become another form of mass culture and its popularity is often equal to that of other mass media. In fact, since the 1990s the number of participant of 'contemporary art' has increased, nearly just as the rise of social media in the same period of time. The emergence of the Web as the new standard communication medium in the 1990s has established a web presence in most cultural fields, allowing a global audience. The challenge in the dynamics of Web 2.0 culture is its constant innovation, energy and unpredictability. Having extensively searched for Media art on the web, an enormous quantity of material have been found: artworks, interviews, exhibition opening videos, exhibition set up, video document, etc. The web is a great resource for art in terms of content and technology. However, all this material is spread around, unclassified and not yet organized and therefore not immediately accessible. Galleries and museums websites, on the other hand, provide information uniquely related to specific artists and works; their own event and openings. Their own commercial interests. Artists use the web as a repository for showcasing their works, as well as providing information to other professionals of the field. The communicating and interactivity feature, not to mention the relation with a larger general public represent - still today - just a minor aspect of Media art presence on the web. Furthermore, communication of contemporary art today is changing, taking advantage of the available technology and the social changes occurred. The analogy cameraman/user needs to be replaced by browser/user, as the audience watches online databases. The concept of user participation becomes even stronger. The viewer interacts, uploads content, takes part into discussion. We are active witnesses of the world of social media - hundreds of millions of people daily uploading and downloading video, audio, and photographs. Media objects fluently and rapidly moving between users, devices, contexts and networks. A number of innovation occur daily and perhaps the most conceptual one is being happening in the development of the Web 2.0 medium itself.

All the new creative tools - web mashups, Firefox plug-ins, Facebook applications, etc.. - are coming out from both large companies like Google and from individual developers. The real challenge may lie in the dynamics of Web 2.0 culture - its constant innovation, its energy, and its unpredictability. Any museum or institution which aims to communicate and be a reference point at a global level is - or is becoming - an active participant of this world. However, in this context communication needs to be global and to comprehend a variety of different information, in different formats. Search and consumption happens at a very fast pace and individual museums' and gallery websites website fail to satisfy user requests. In 
this consumption era an aggregation portal seems to be a possible solution to maintain Media art communication lively.

While museums become a media laboratory, experimenting with technology, and exploring its different uses, this analysis moves toward the role Media play in a strategic communication of contemporary art, including social media, and more generally Web 2.0. As a response to the explosion of user-generated 'content' available in digital form (web sites, blogs, forum discussions, digital photo, video, music, etc), Web 2.0 companies created powerful platforms designed to host this content. MySpace, Facebook, Flickr, YouTube, and hundreds of other social media sites have become available worldwide. Thus, the details of everyday life of millions of people became public. Social media platforms offer users nearly unlimited space for storage and plenty of tools to organize, promote and broadcast thoughts, opinions, behaviours and Media.

\section{CONCLUSION}

The past decades have witnessed the explosive growth of the World Wide Web, which has rapidly transformed personal communication and much more, including innovations such as blogging, downloading and open-source software, forcing institutions to adopt whole new ways of thinking, working and doing business. Museum-related professionals also find themselves at a time of change, with variation in their professional missions, an expansion of their target audience, and new options for delivering, presenting and making accessible their content.

Whilst the technology revolution has been changing museum practice, there has also been a adjustment among many art institutions in their core mission. Whereas it used to be exclusively to collect, preserve and exhibit works of art, that mission has now expanded in different ways, including the outreach to new audiences. Within this frame, the reflection of relationship between museum, art spaces and the web become crucial. While social networks are taking a growing part in everyday life and their presence grows in museums, this analysis suggests the development of a communication strategy for contemporary art, reflecting on the way museums/art spaces and institutions go on social networks, what they seek on those networks, what are the benefits. The use of media must address to the audience's needs.

Indeed, Web 2.0 technologies are more than just web-based games and social networks: they are virtual environments which are building communities of thought and practice. What are the true benefits? What are the potential conflicts or roadblocks? There is the opportunity to expand the reach for the topic of research, to provide opportunity for engagement with new audiences, and to provide an outreach service to the community. It also allows to explore new means of knowledge work using digital technologies. Furthermore, the web could be used to engage communities in better understanding and appreciation of culture through partnership among organizations, museums, galleries, artists, experts of the fields and virtual communities. Communication tools enable members of the virtual community to provide reflections and engage in dialogue, as well as to contribute their own content. Successful interaction of such kind is an attractive way of providing complementary expertise in addressing needs of common concern and tasks that require a range of knowledge areas. As professions evolve in their missions and their roles expand and intersect with those of other disciplines, the potential for effective synergistic collaboration and interaction increases. With a collaboration among museums, content specialists, artists, there are roles for partners 
providing service to the end-user, as well as roles for end-users engaging with the content. Individual partners can play different roles according to their degree of expertise, level of commitment, and ability to participate in terms of time and resources.

In creating web-based materials the goals are to create interest in and understanding of the topic; provide a means for further knowledge of the topic; provide mechanisms to engage in dialogue; and provide a means for participatory experiences.

In designing the site to establish relevance and connection, this project envisions a resource containing information, enriched by images, maps, and links, to make clear the relevance of media art to a contemporary audience. The site would also contain material to encourage people to make their own connections. Indeed, focusing on Media art, the aim is to create a virtual space in which Media art projects find place. This website would be a space dedicated to Media art, displaying new forms of artistic creation and new ways of communication with the public in a multi-disciplined setting and new ways of relating. It would represent a new way of life for Media art, based on the need to create a 'conversation' between the audience/visitors. In fact, within Web 2.0 the 'conversation' structure (web info-structure and software) allow conversations to be distributed in space and time: people can respond to each other regardless of their locations and conversations could in theory go on indefinitely. The web indeed is a million of such conversations taking place at the same time and this website intends to offer the Media art community a place for plentiful conversations. 


\section{REFERENCES}

Brougher, K., Strick, J., Wiseman, A., \& Zilczer, J. (2005) Visual Music, Synaesthesia in Art and Music Since 1900. London: Thames and Hudson.

Benjamin, W. (1936) "The Work of Art in the Age of the Mechanical Reproduction", in Illuminations (1969) Ed. Hannah Arendt. Trans. Harry Zohn. New York: Schocken Books.

Crary, J.(1990) Techniques of the Observer: On Vision and Modernity in the Nineteenth Century. Cambridge, M.A.: The MIT Press.

Greene, R. (2004) Internet Art. London: Thames and Hudson.

King, G. \& Krzywinska, T. eds., (2002) ScreenPlay: Cinema/Videogames/Interfaces. London: Wallflower Press.

Levinson, P. (1997) The Soft Edge: A Natural History and Future of the Information Revolution. London: Routledge.

Moser, M. A. ed., (1996) Immersed in Technology: Art and Virtual Environment. Cambridge, M.A.: The MIT Press.

O’Reilly, T. (2005) 'What is Web 2.0.: Design Patterns and Business Model for the Next Generation of Software' [internet] 30 Sept. Available at: http://www.oreillynet.com/pub/a/oreilly/tim/news/2005/09/30/what-is-web-20.html?page=4 [Accessed: 23 June 2010].

Paolini, P., Mainetti, L. \& Bolchini, D. (2006) Progettare Siti Web e Applicazioni Mobili. Milan: McGraw-Hill Companies.

Pisters, P., (1998) From Eye to Brain: Gilles Deleuze: Refiguring the Subject in Film Theory. Amsterdam: PhD, University of Amsterdam.

Plato. (c. 360 b.c.e.) The RepublicTrans. B. Jowett (2008). New York: Comino Inc

Sumitomo, F. \& Shikata, Y. (2005) Art meets Media: Adventures in Perception. Tokyo: NTT Publishing Co.

Weibel, P. \& Druckery, T. eds,. (2001) Net condition: Art and Global Media. Cambridge, M.A.: The MIT Press. 